\title{
FPGA-based Embedded System for Wind Tunnel Variable-Geometry Nozzle Positioning
}

\author{
Biljana Ilić ${ }^{1)}$ \\ Mirko Milosavljević ${ }^{1)}$
}

\begin{abstract}
Over the last few decades, the accuracy requirements for wind tunnel testing have become much more stringent as aircraft industry strives to achieve the best performance of their products. Investments in advanced capabilities are necessary to obtain more accurate test results more efficiently, ensuring that the wind tunnels stay productive well into the future. The VTI Belgrade T-38 wind tunnel responded to these challenges by applying a hierarchical approach to design a distributed multilevel control system, a part of which is the variable-geometry nozzle positioning system, presented in this paper. It follows the hierarchy of the entire wind tunnel control system, with critical positioning loops at the field-programmable gate array (FPGA), and the user interface with real-time data analysis capability implemented on a central wind tunnel computer. In addition to more accurate positioning, the FPGA-based control system significantly improved overall operation efficiency, speed and reliability. Since the nozzle geometry uniquely determines supersonic Mach number, the improved positioning accuracy is verified in wind tunnel tests
\end{abstract}

Key words: nozzle, wind tunnel, FPGA, position control, real-time system, actuators, sensors.

\section{Introduction}

$\mathrm{I}_{\mathrm{s}}^{\mathrm{N}}$ wind tunnel operation, the imperative is to achieve geometric, kinematic and dynamic similarity between a reduced-scale model tested in a wind tunnel and a full-scale object. In a supersonic wind tunnel, aerodynamic forces generated between the air and the model mostly depend on an important property of the air - compressibility [1]. A similarity parameter used to model these effects is Mach number. A desired Mach number should be achieved in the wind tunnel test section, where a model is situated, and establishment of the flow which is uniform, parallel to the wind tunnel axis and with constant Mach number distribution across the test section is an additional requirement. The achievement of these conditions in a supersonic wind tunnel primarily depends on the nozzle geometry.

The nozzles for supersonic wind tunnels are normally made two-dimensional, and this necessitates achieving carefully controlled shapes on two walls, with remaining two walls being flat [2]. Through the wind tunnels history there were several nozzle designs applied, including fixed-block design, plug-type and grating-type designs, but the most versatile method of obtaining the variable geometry includes flexible plates [3]. The flexible plates are contained between two parallel walls and they are bent to the required shape for the desired Mach number. The most direct method of supporting plates is by the use of a series of jacks. These jacks have their inner ends attached to the plate and their outer ends attached to the structure surrounding the nozzle. The flexible plate acts as a spline which is constrained at a number of closely spaced points. A family of nozzle shapes is established such that the Mach number interval from one shape to the next is small, and therefore continuous Mach number variation is achieved. However, aerodynamic geometry must be compatible with the physical shape of a spline constrained at a number of points.

There are various methods for calculating a required flexible nozzle geometry [4], but its mechanical, structural and aerodynamic design has been essentially unchanged for decades. Complex numerical simulations are made possible by fast computers, but they are applied mainly in fine tuning of a geometry obtained by the fundamental aerodynamic calculation [5]. However, ever more stringent requirements for measurement quality led to stricter demands for the nozzle positioning system regarding accuracy, speed and reliability.

A variable-geometry nozzle positioning system can range from a simple single-sensor single-actuator design [6] to a complex multi-sensor multi-actuator system [7], with a number of components that are expected to work in parallel, at high-speed and in tight synchronization with each other. Field-programmable gate array (FPGA) is specifically suited to fulfillthese requirements. FPGA is being increasingly used in embedded control systems [8] as a low-cost and highperformance solution [9]. Since all of the logic is implemented on hardware, FPGA brings obvious advantage in terms of speed and reliability. Each task utilizes a different set of the gates with the result that multiple tasks can run in parallel, which makes FPGA suitable for complex multicomponent systems with strict timing requirements $[10,11]$.

In this paper, design and implementation of a FPGA-based embedded positioning system for the VTI Belgrade T- 38 wind tunnel nozzle with two symmetrical, $1.5 \mathrm{~m} \times 11 \mathrm{~m}$ flexible plates, are discussed. The nozzle positioning is based on 38 electric motors driving 76 screw stops with 19 position sensors as feedback, and 38 hydraulic cylinders driving nozzle flexible plates and forming a shape which corresponds to a desired Mach number. The required nozzle position accuracy is $0.01 \mathrm{~mm}$, corresponding to Mach control accuracy of $0.2 \%$.

\footnotetext{
1) Military Technical Institute (VTI), Ratka Resanovića 1, 11132 Belgrade, SERBIA

Correspondence to: biljana.ilic@,icloud.com
} 
In the first section of the paper, blowdown-type wind tunnel operation is briefly introduced, with emphasis on aerodynamic operation of a variable-geometry nozzle. The VTI Belgrade T-38 wind tunnel nozzle mechanical design is explained. Hardware and software architectures of the nozzle positioning system are detailed. Then, the contribution of the implemented system to the wind tunnel operation is discussed. The VTI Belgrade T-38 wind tunnel experimental data are presented for the entire supersonic range, from Mach 1.5 to Mach 4.0. The paper is concluded by discussing how added advanced capabilities can make test facilities productive well into the future.

\section{Wind tunnel variable-geometry nozzle}

\section{Aerodynamic Operation}

The variable-geometry nozzle in the VTI Belgrade T-38 wind tunnel [12] is considered in this paper. However, the same operation principle applies to all wind tunnel facilities.

The VTI Belgrade T-38 wind tunnel is a blowdown-type [13] test facility operating at subsonic, transonic and supersonic speeds, with Mach number range of $0.2-4.0$. Its schematics with main components is given in Fig.1.

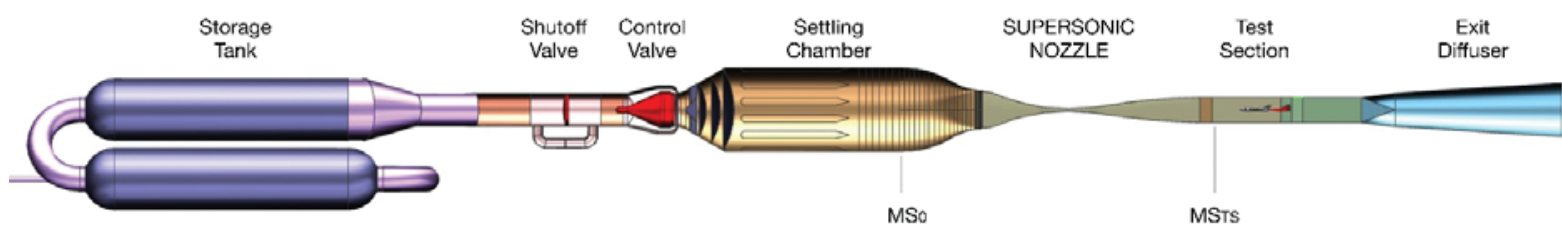

Figure 1. The VTI Belgrade T-38 supersonic wind tunnel schematics

Air is stored in the $2600 \mathrm{~m}^{3}$ tank, pressurized up to $2 \mathrm{MPa}$. The pressure difference establishes a flow in the $1.5 \mathrm{~m} \times 1.5 \mathrm{~m}$ test section, and the air flows from the tank to the atmosphere. The flow must be established through the wind tunnel circuit as quickly as possible. It is critical to efficient operation of the facility, aimed to save valuable test time. Following the wind tunnel start, the flow parameters must be maintained close to their required values for a duration of a wind tunnel test. These requirements must be met over a wide range of operating conditions. There are two basic flow parameters that are expected to be achieved and maintained around the model situated in the test section of a blowdown wind tunnel: stagnation pressure and Mach number.

The desired stagnation pressure is achieved by changing position of the control valve as the tank pressure decreases. The stagnation pressure range possible in the T-38 wind tunnel is from $0.12 \mathrm{MPa}$ to $1.5 \mathrm{MPa}$, depending on the Mach number. The stagnation pressure is measured at the settling chamber exit ( $\mathrm{MS}_{0}$ cross-section in Fig.1).

After the settling chamber, the flow is accelerated through the nozzle to achieve the desired flow parameters in the test section. In the supersonic range, the Mach number in the test section is entirely determined by the nozzle geometry. Consequently, the unique nozzle geometry corresponds to each supersonic Mach number, from 1.5 to 4.0. In the subsonic (Mach 0.2-0.8) and transonic (Mach 0.8-1.4) test regimes, the nozzle is preset to the desired shape, but the desired Mach number is achieved using the additional second throat system and blow-off system, respectively [14]. The static pressure is measured at the nozzle exit $\left(\mathrm{MS}_{\mathrm{TS}}\right.$ crosssection in Fig.1).

The task of the positioning system is to set the nozzle to a shape required for any Mach number in the facility's operating range. In the T-38 wind tunnel, there is a database of nozzle geometries corresponding to all Mach numbers in the range from 0.2 to 4 [14].

In wind tunnel practice, Mach number in the test section is calculated using the basic isentropic relation [15]:

$$
M=\sqrt{\frac{2}{\kappa-1}}\left[\left(\frac{P_{S T}}{P_{0}}\right)^{-\frac{\kappa-1}{\kappa}}-1\right]
$$

where $M$ is Mach number in the test section, $P_{S T}$ is static pressure, $P_{0}$ is stagnation pressure, and $\kappa$ is the ratio of air specific heats.
Since Mach number is calculated using measured values of stagnation and static pressures, its control accuracy depends on measurement uncertainties of the appropriate pressure sensors, in addition to the nozzle geometry. Consequently, a Mach number control accuracy calculation must include propagation of the pressure measurement uncertainties to the Mach number uncertainty [16].

\section{Nozzle Components}

The VTI Belgrade T-38 wind tunnel variable-geometry nozzle has 19 jack stations, supporting upper and lower $1.5 \mathrm{~m}$ $\times 11.0 \mathrm{~m}$ flexible plates lengthwise, between two parallel fixed side walls (Fig.2).

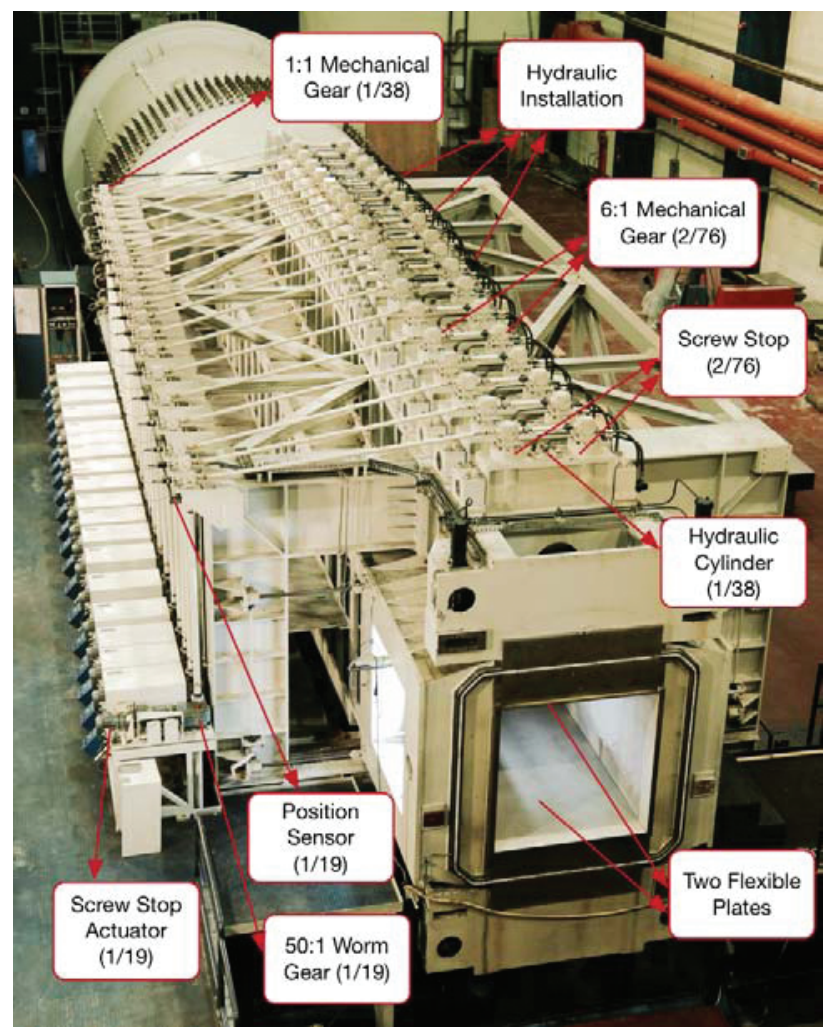

Figure 2. The VTI Belgrade T-38 wind tunnel variable-geometry nozzle.

The drawing of an individual jack station is shown in Fig.3. Each of 19 jack stations has four identical screw stops, two on the upper side and two on the lower side. Screw stops at different jack stations have different strokes, ranging from 5 
$\mathrm{mm}$ to $810 \mathrm{~mm}$. Their position is measured by a rotary position sensor mounted directly to the shaft of one of four screw stops for each jack station.

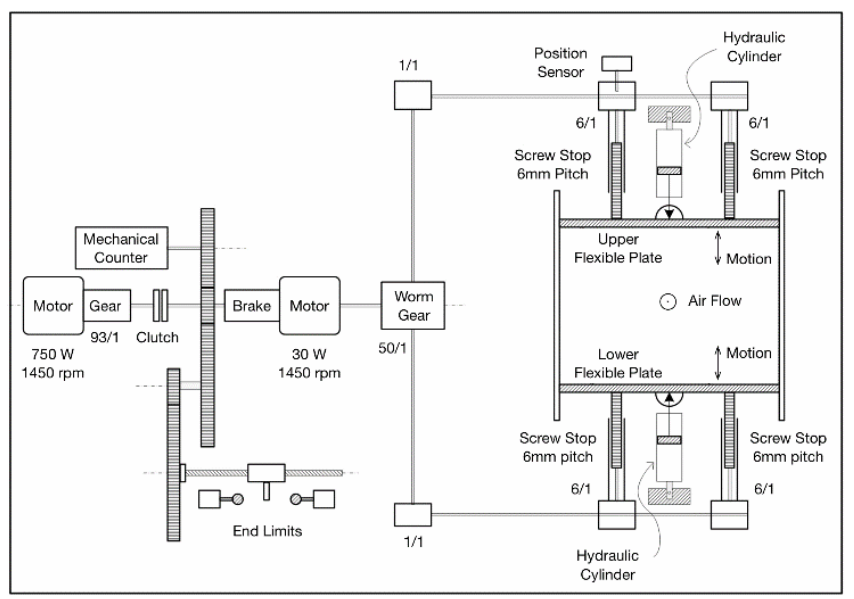

Figure 3. An individual nozzle jack station with sensors and actuators

A screw stop actuator consists of a high-power electric motor, a low-power electric motor, a clutch and a holding brake at each station, coupled with four screw stop shafts over a 50:1 warm gear, two 1:1 mechanical gears, four 6:1 mechanical gears and a system of rods. These components comprise a structure surrounding the nozzle plates, and their purpose is to achieve the required geometry.

Each jack station also has two hydraulic cylinders, an upper and a lower one. The cylinder body is attached to the fixed nozzle structure, while the piston rod is coupled with a flexible plate. All cylinders are driven by the common hydraulic system, which can operate at low or high pressure. The hydraulic system uses pressure and temperature sensors.

Electromechanical over-curvature sensors are distributed along the length of the flexible plates, eight between each consecutive pair of jack stations. Mechanical end limits are situated in the gear box of each jack station.

Therefore, the VTI Belgrade T-38 wind tunnel nozzle is a multi-sensor multi-actuator system with mechanical, electrical and hydraulic components, consisting of 19 high-power and 19 low-power electric motors driving 76 screw stops, 19 position sensors as feedback for screw stop positions, 38 hydraulic cylinders, pressure and temperature sensors as feedback for hydraulic system and 144 over-curvature sensors as interlocks with the nozzle positioning procedure.

\section{Nozzle Positioning Requirements}

The positioning requirements are dictated by the variablegeometry nozzle design. First, the hydraulic system has to be set to low pressure and hydraulic cylinders have to move the flexible plates to their innermost profile, to enable unobstructed movement of screw stops. Then the appropriate commands are sent to the motors, based on the desired positions and the measured current positions. The difference between desired and current positions determines speed and direction of screw stops movement. In the most frequent scenario, after releasing the brake, the high-power motors are initially driven to move the screw stops toward the new positions. When a screw stop reaches a pre-set distance from its desired position, the movement is switched to the lowpower motor with appropriate clutching action. The lowpower motor is stopped by applying the brake when the desired position is reached. To eliminate backlash effect, it is recommended that the screw stops approach their desired positions from the same direction. Consequently, when approaching the new position in the reverse direction, the screw stops should go past their desired positions, reverse the direction of travel and approach the final positions from the forward direction. After setting all screw stops, the hydraulic system is set to high pressure to allow hydraulic cylinders to pull the flexible plates back against the newly set screw stops.

\section{Nozzle positioning system}

\section{Sensors and Actuators}

The VTI Belgrade T-38 wind tunnel has been in operation since 1980s and, until recently, the nozzle was used with its original positioning system. Sensors used as position feedback in the initial nozzle positioning system were multispeed resolvers [14]. Resolver inputs and their reference were fed to the multichannel resolver-to-digital conversion unit, which sequentially converted resolver signals to 19-bit binary data, with position resolution of $0.002 \mathrm{~mm}$. Each conversion gave a feedback position from one of 19 resolvers. The minimum time between consecutive conversions was $6 \mathrm{~ms}$. The control computer loop time was $60 \mathrm{~ms}$, and it was time needed to read a position, decide an action and issue a command to an actuator for a single jack station. For an entire 19-stations control cycle, it was needed $19 \times 60=1140 \mathrm{~ms}$. Obviously, overall system performance was severely limited by using resolvers and the resolver-to-digital conversion unit. In addition to the sequential position conversion that prevented effective migration to platforms such as FPGAs, with parallel execution capability and higher speed of operation, the equipment started to work unreliably after decades of exploitation.

Within a new implementation of the nozzle control element, resolvers were replaced by HengstlerAcuro AC 58 absolute shaft multiturn encoders [17] with BiSS interface [18]. The encoders have 26-bit resolution, 14 bits per revolution and 12 bits for a number of revolutions. Resolution with regard to the nozzle plates' position is $0.00009 \mathrm{~mm}$, which is more than 20 times better than in the original implementation. Also, the use of sensors with digital output eliminated the need for an analog-todigital conversion unit [19].

Actuators used in the original positioning system are retained. Each station actuator consists of two Eberhard Bauer D-7300 motors on the same shaft: a high-power $750 \mathrm{~W}$ motor and a low-power $30 \mathrm{~W}$ motor. Switching between them is done with the appropriate clutching action. Screw stops driven by high-power and low-power motors have speeds of 3.5 $\mathrm{mm} / \mathrm{s}$ and $0.04 \mathrm{~mm} / \mathrm{s}$, respectively [14].

\section{Hardware and Software Architectures}

The nozzle positioning system is one of 16 control elements within the overall VTI Belgrade T-38 wind tunnel control system, which are expected to work both independently and in tight synchronization with each other. Within the project aimed to analyze advanced capabilities that could bring more efficient operation and more accurate test results, detailed analysis of the control requirements was done [20]. The centralized control paradigm used in the past was abandoned and a hierarchical approach is applied to design a distributed multi-level wind tunnel control system [21]. The platform chosen for implementation is the NI CompactRIO programmable automation controller (PAC) [22]. It consists of the embedded real-time controller and the reconfigurable chassis. The NI cRIO-9024 controller features an industrial real-time processor for deterministic real-time applications. The NI cRIO-9118 eight-slot chassis has a user- 
programmable FPGA, which enables a low-level hardware access to any I/O module, while communication with the realtime processor is realized using a high-speed PCI bus. The real-time processor is optimized for control loops running at less than $1 \mathrm{kHz}$, while the FPGA should be used for faster loops, up to $40 \mathrm{MHz}$. The VTI Belgrade T-38 wind tunnel control system is entirely implemented on two NI CompactRIO programmable automation controllers and the central control computer that communicates with both controllers via Ethernet ports.

The nozzle positioning system is implemented on one of the controllers. Due to high-channel counts needed for the other control elements, the platform is expanded with the NI 9144, 8-slot EtherCAT slave chassis. The master controller communicates deterministically with the slave chassis via the second Ethernet port.

Seven I/O modules handling the nozzle tasks are all based on the slave chassis, with 93 digital I/O channels (Fig.4). Digital outputs to electric actuators and hydraulic system, 67 in total, are transmitted from three NI 9477 32-channel, $8 \mu \mathrm{s}$ sinking digital output modules. Digital inputs from position, pressure and temperature sensors, 26 in total, are fed to four NI 9401, 8 channel, high-speed, bidirectional DI/O modules, with maximum I/O switching frequency per channel of 9 $\mathrm{MHz} / 5 \mathrm{MHz}$, respectively.

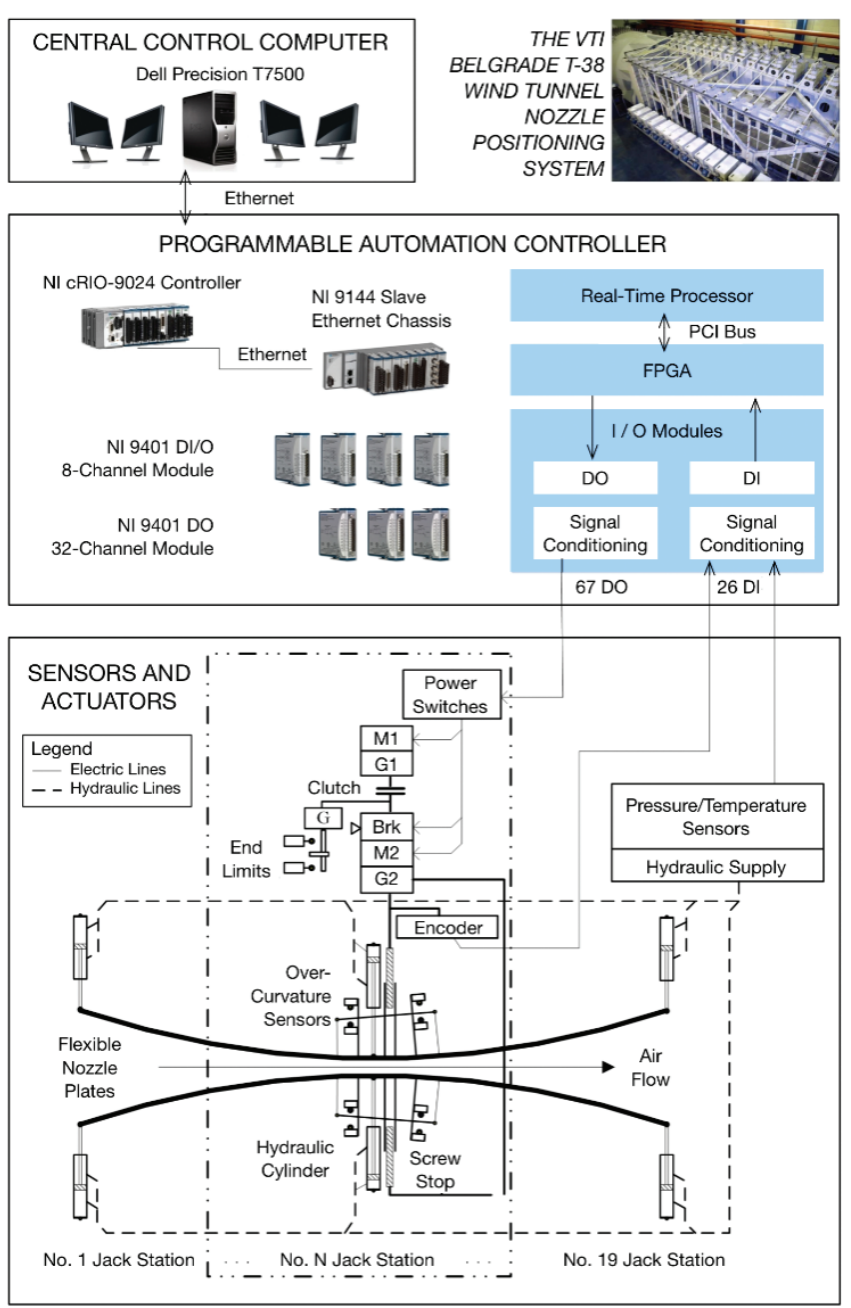

Figure 4. Architecture of the nozzle positioning system

Programming of the controller is performed on the central wind tunnel computer, using LabVIEW development environment [22]. The FPGA low-level software handles critical positioning loops, the real-time high-level software implements the data acquisition, while the user interface with real-time data analysis capability works at the central computer [20].

\section{Implementation}

As a position feedback from 19 jack stations, 19 absolute multiturn encoders with BiSS interface are used. For correct transfer of data, 30 impulses (clock pulse brush) must be applied to the clock input of an absolute shaft encoder. As soon as a clock pulse brush is applied to the clock pulse input, the actual angle information is latched for a limited time. The required clock frequency for this type of encoder is 100-400 $\mathrm{kHz}$, and time available to read position data is $20 \mu \mathrm{s}$.

For handling position data, three NI $9401 \mathrm{DI} / \mathrm{O}$ modules are employed. The first NI 9401 module is configured for four digital inputs and four digital outputs, while the remaining two NI 9401 modules are configured for inputs only-eight inputs per module. A single digital output is used for the clock pulse brush applied simultaneously to the clock inputs of all 19 encoders. Nineteen inputs are used for encoder position data.

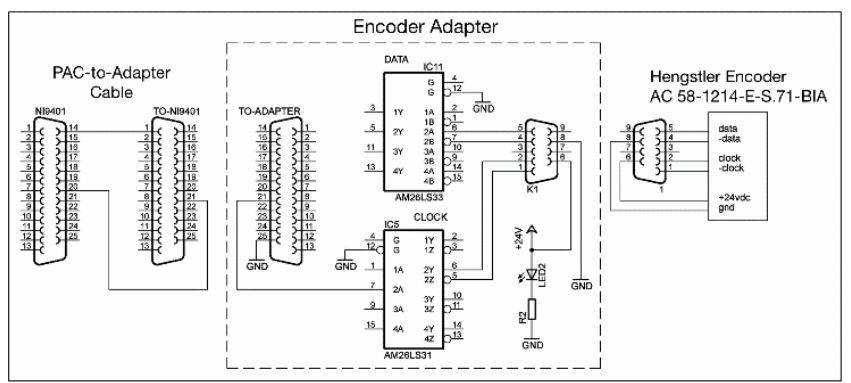

Figure 5. A single encoder connection to the NI $9401 \mathrm{DI} / \mathrm{O}$ module

Schematics of a single encoder connection to the DI/O modules is shown in Fig.5. The identical principle is used to connect all nineteen encoders to the NI 9401 modules, but only one is shown for clarity. Note that a single clock pulse brush is applied to the clock inputs of all 19 encoders at the same time. Consequently, the clock inputs of all encoders are connected to a single NI 9401 digital output.

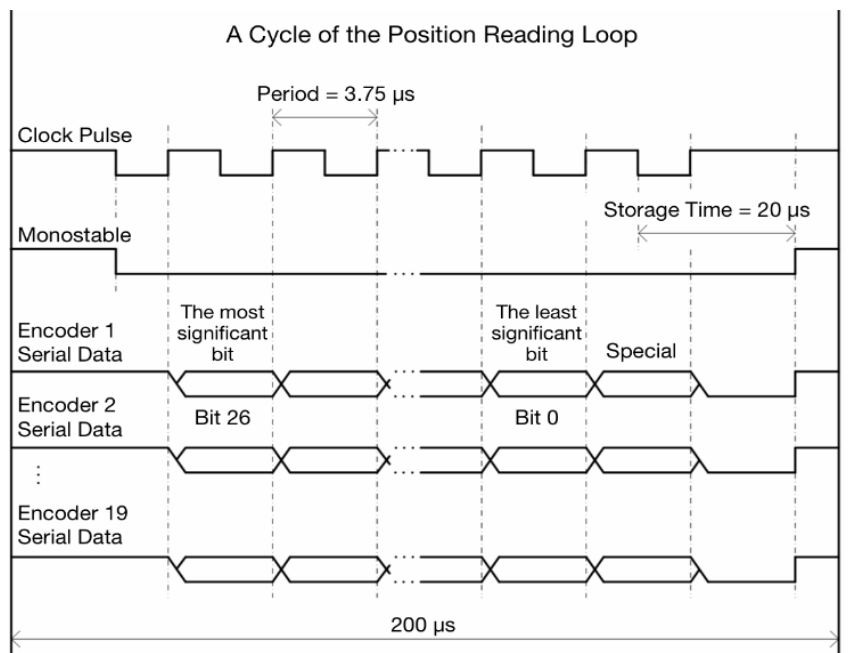

Figure 6. A cycle of the position reading loop executed on the FPGA

Clock pulse brush with frequency of $267 \mathrm{kHz}$ is applied. With each clock rising edge, the next bit is shifted to the serial data output of each encoder. After a full clock pulse brush consisting of 30 impulses, 30 bits of data are read for each encoder -26 bits for position and four special bits. Positions from all encoders are then interpreted and they are available within one loop cycle (Fig.6). In the next loop cycle, the clock pulse brush is applied again and the same procedure is repeated. Loop rate of $5 \mathrm{kHz}$ is used, which means that 
current positions from all 19 encoders are available every $0.0002 \mathrm{~s}$.

The command loop, within which commands are issued to the actuators, runs in parallel with the position reading loop, with the same rate of $5 \mathrm{kHz}$. Position changes of all encoders are detected in each reading loop cycle, current and desired positions are compared in the command loop, and appropriate commands are issued simultaneously to all actuators.

While the main positioning task is implemented on the FPGA level, the real-time level is used for position data acquisition. Each nozzle positioning procedure is logged to a file, which is automatically transferred to the central computer and stored to the wind tunnel database. By analyzing data, it is possible to notice any irregularities in the nozzle behavior, and solve them proactively. It is an important feature for complex systems such as the nozzle in the VTI Belgrade T-38 wind tunnel, with mechanical, hydraulic and electric components and a high number of sensors and actuators.

User interface with real-time data analysis capability provides simulation of the nozzle state on the central control computer in the wind tunnel control room. In regular circumstances, the nozzle geometry for the desired Mach number is chosen from the VTI Belgrade T-38 wind tunnel database and it is set automatically.

\section{Discussion}

Abandoning the previous sequential approach and migrating to the PAC platform with FPGA capability has brought significant improvements to the variable-geometry nozzle positioning in the VTI Belgrade T-38 wind tunnel related to speed, reliability, accuracy and overall efficiency of operation.

Using the FPGA and a parallel computing approach, the speed of operation has been improved for several orders of magnitude. Introduction of absolute encoders enabled using parallel execution capabilities of the FPGA-based embedded controller, where truly parallel nature of the FPGA allows simultaneous execution of many operations. Specifically, a control cycle comprising reading positions of all jack stations, deciding actions and issuing appropriate commands to all actuators is almost 6000 times faster now than in the original implementation ( $0.2 \mathrm{~ms}$ versus $1140 \mathrm{~ms})$.

In addition to much higher speed of operation, implementation of application logic in hardware circuits is considered a more reliable alternative for the complex nozzle system, than executing on top of an operating system, drivers and application software, like in processor-based systems.

In the original implementation, the desired position accuracy of $0.01 \mathrm{~mm}$ could not be achieved automatically, due to sequential computing approach dictated by poor computer performance and poor choice of position sensors. When all screw stops were moving simultaneously, the time between consecutive control actions for a specific screw stop was unacceptably long. In this scenario it was not possible to stop screw stops in time to achieve the desired accuracy. The optimum algorithm adopted in these conditions included moving screw stops in series of only several stations. Despite the efforts, the desired accuracy could rarely be achieved automatically, except by moving screw stops for each station successively. It was unacceptable in the original wind tunnel control system, capable to execute only one task at a time, meaning that the nozzle positioning prevented preparations of other systems for the next test. Based on these considerations and general criteria established for a good flow quality [23], it was decided to accept positioning accuracy of $0.02-0.03 \mathrm{~mm}$, barely corresponding to the Mach number accuracy of $0.5 \%$.
Positioning within the new system is performed in parallel with other wind tunnel tasks and by moving all screw stops simultaneously, with immediate achievement of the position accuracy of $0.01 \mathrm{~mm}$, corresponding to a higher Mach number control accuracy of $0.2 \%$, which has been verified in wind tunnel tests for the entire supersonic range, from Mach 1.5 to 4.0. Here it should be emphasized that the Mach number control accuracy in a wind tunnel test includes both maximum Mach number time variation and measurement uncertainty.

Mach number measurement uncertainty is estimated based on the statistical theory of error propagation [24]. Since freestream Mach number in the test section is calculated using the isentropic equation (1), its measurement uncertainty depends of uncertainties of two directly and independently measured flow parameters: stagnation pressure $\left(P_{0}\right)$ and static pressure $\left(P_{S T}\right)$. Precision sensors Mensor CPT-6100 [25] are used for pressure measurement, with uncertainty of $0.01 \%$ of reading. Both sensors are absolute, with measuring ranges of $1.7 \mathrm{MPa}$ and $0.7 \mathrm{MPa}$ for stagnation and static pressure, respectively.

According to the error propagation theory [23], the Mach number measurement uncertainty is calculated as follows:

$$
\frac{E_{M}}{M}=\left[\left(\frac{P_{0}}{M} \frac{\partial M}{\partial P_{0}} E_{P_{0}}\right)^{2}+\left(\frac{P_{S T}}{M} \frac{\partial M}{\partial P_{S T}} E_{P_{S T}}\right)^{2}\right]^{1 / 2}
$$

where $E_{M}, E_{P_{0}}$ and $E_{P_{S T \mid}}$ are measurement uncertainties of Mach number, stagnation pressure and static pressure, respectively. Sensitivity coefficients for stagnation pressure and static pressure in equation (2) are obtained using (1):

$$
\begin{gathered}
S_{P_{0}}=\frac{P_{0}}{M} \frac{\partial M}{\partial P_{0}}=\frac{1}{\kappa}\left(\frac{P_{0}}{P_{S T}}\right)^{\frac{\kappa-1}{\kappa}}\left\{\frac{2}{\kappa-1}\left[\left(\frac{P_{0}}{P_{S T}}\right)^{\frac{\kappa-1}{\kappa}}-1\right]\right\}^{-1} \\
S_{P_{S T}}=\frac{P_{S T}}{M} \frac{\partial M}{\partial P_{S T}}=-\frac{1}{\kappa}\left(\frac{P_{0}}{P_{S T}}\right)^{\frac{\kappa-1}{\kappa}}\left\{\frac{2}{\kappa-1}\left[\left(\frac{P_{0}}{P_{S T}}\right)^{\frac{\kappa-1}{\kappa}}-1\right]\right\}^{-1}
\end{gathered}
$$

Mach number measurement uncertainty estimated based on equations (2-4) is shown in Fig.7 (green line), for Mach number range $1.5-4.0$.

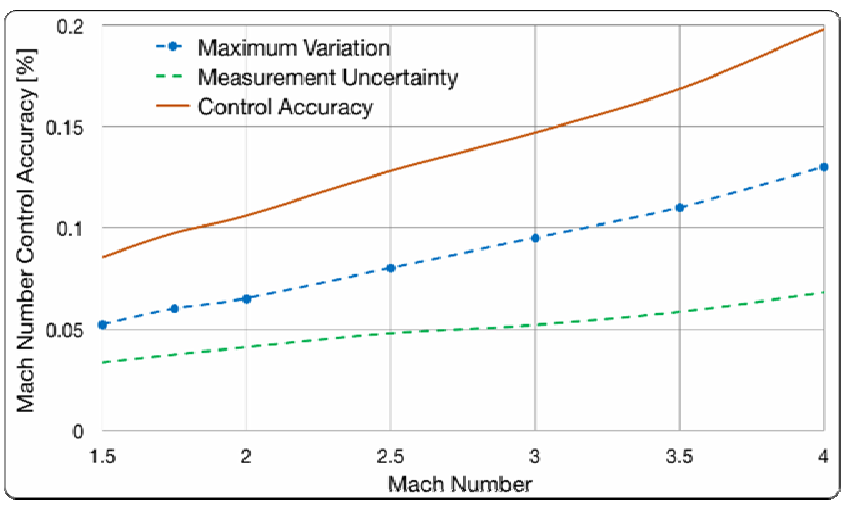

Figure 7. Mach number control accuracy in the VTI Belgrade T-38 wind tunnel supersonic range.

Maximum Mach number time variations calculated using the statistical analysis of the data obtained in the repeated wind tunnel tests at Mach numbers 1.5, 1.75, 2.0, 2.5, 3.0, 3.5 and 4.0 are also shown in Fig.7 (blue line).

Sum of the measurement uncertainty and time variation for each Mach number gives the Mach number control accuracy distribution for the VTI Belgrade T-38 wind tunnel supersonic range, from Mach 1.5 to 4.0, represented in Fig.7 (red line). 
Fig.7 shows that the Mach number control accuracy of $0.2 \%$ is achieved for the full wind tunnel supersonic range. As expected, control error increases with Mach number. It is explained by more demanding flow establishment process at low mass flows, corresponding to high Mach numbers [1].

\section{Conclusion}

Over the last few decades, several critical needs for aeronautical testing have been developed. In addition to more stringent accuracy requirements, the cost of testing is so high that customers now wish to obtain much more from each test entry for the facilities. Since experimental testing is still the best way to determine "off-design" conditions where analytical and numerical tools cannot predict performance reliably, thoughtful investments in advanced capabilities and testing technologies are necessary to make the wind tunnel facilities as productive as possible.

The aeronautical testing community should adopt practices that enhance the use of the facilities, ensuring they will be viable well into the future.In the VTI Belgrade T-38 wind tunnel, particular attention has been given to flow control techniques. The centralized control paradigm from the past was abandoned and a hierarchical approach to design a distributed multi-level flow control system is applied. The effect of the newly designed system on the supersonic Mach number control accuracy is discussed in this paper. However, the paradigm change in the VTI Belgrade T-38 wind tunnel has also given many other significant contributions to the flow control quality, resulting in novel methods that are easily adaptable to any blowdown-type facility [21].

\section{References}

[1] ILIĆ,B., MILOSAVLJEVIĆ,M., ISAKOVIĆ,J.: (2016, Mar.), Modelbased stagnation pressure control in a supersonic wind tunnel,FME Transactions. [Online]. 44(1), pp.1-9. Available:

http://www.mas.bg.ac.rs/ media/istrazivanje/fme/vol44/1/01 biljana ilic_et_al.pdf

[2] MOREL,T.: (1977, Jun.). Design of two-dimensional wind tunnel contractions, J. Fluids Eng. [Online].99(2), pp.371-377. Available: $\mathrm{http}$ ://fluidsengineering.asmedigitalcollection.asme.org/article.aspx? articleid $=1423914$

[3] KENNEY,J.T., WEBB,L.M.: A Summary of the Techniques of Variable Mach Number Supersonic Wind Tunnel Nozzle Design, NATO AGARD, Paris, France, AGARDograph No.3, 1954.

[4] WOLF,S.W.D.: Supersonic Wind Tunnel Nozzles: A Selected, Annotated Bibliography to Aid in the Development of Quiet Wind Tunnel Technology, NASA, Washington, D.C, Tech. Rep. CR-4294, Jul. 1990.

[5] ANDERSON,J.D.: Supersonic nozzle design, in Modern Compressible Flow with Historical Perspective, 3rd ed., New York: McGrawHill,2003, pp.397-403.

[6] JUHANY,K.A., HUSAINI,H.E.: (2007, Jan.). Investigation of a singlejack flexible supersonic nozzle, Presented at $45^{\text {th }}$ AIAA Aerospace Sciences Meeting and Exhibit.[Online]. Available: http://arc.aiaa.org/doi/abs/10.2514/6.2007-958

[7] WARNER,M., SUMMERS,W., DAVIS,M.: (1982, Mar.). A review of two-dimensional nozzle design techniques, Presented at $12^{\text {th }}$ AIAA Aerodynamic Testing Conference .[Online]. Available: http://arc.aiaa.org/ doi/abs/10.2514/6.1982-609

[8] YIANNACOURAS,P., STEFFAN,J.G., ROSE,J.: (2007, Feb.). Exploration and customization of FPGA-based soft processors, IEEETrans. Comput.-Aided Design Integr. Circuits Syst. [Online]. 26(2), pp.266-277. Available: http://ieeexplore.ieee.org/document/4068937/

[9] LIN,F.J., HUNG,Y.C., CHEN,S.Y.: (2009, Apr.). FPGA-based computed force control system using Elman neural network for linear ultrasonic motor, IEEETrans. Ind. Electron. [Online]. 56(4), pp.1238-1253. Available:

http://ieeexplore.ieee.org/document/4663727/

[10] GARCIA,J.J., HERNANDEZ,A., URENA,J., GARCIA,E.: (2016, Jun.). FPGA-based architecture for a multisensory barrier to enhance railway safety, IEEETrans. Instrum. Meas. [Online].65(6), pp.1352-1363. Available: http://ieeexplore.ieee.org/document/7442865/

[11] MACHADO,J.F., MARINO,P., POZA,F., DOMINGUEZ,M.A., FONTAN,F.P.: (2014, Dec.). FPGA-based instrument for satellite beacon monitoring on propagation experiments, IEEETrans. Instrum. Meas. [Online].63(12), pp.2761-2770. Available: http://ieeexplore.ieee.org/document/6814928/

[12] MEDVED,B., ELFSTROM,G.M.: (1986, Mar.). The Yugoslav $1.5 \mathrm{~m}$ trisonic blowdown wind tunnel, Presented at $14^{\text {th }}$ AIAA Aerodynamic Testing Conference.[Online]. Available: http://arc.aiaa.org/doi/abs/10.2514/6.1986-746

[13] BALACHANDRAN,P.: Wind Tunnel, in Fundamentals of Compressible Fluid Dynamics, New Delhi: Prentice Hall of India, 2006, pp.346-350.

[14] ILIĆ,B., MILOSAVLJEVIĆ,M.: A new control system for the flexible nozzle in the T-38 trisonic wind tunnel, in Proc. $6^{\text {th }}$ Int. Sci. Conf. Defensive Technol., 2014, pp.67-72.

[15] ANDERSON,J.D.: Isentropic Relations, in Modern Compressible Flow with Historical Perspective, 3rd ed., New York: McGraw-Hill, 2003, pp.29-32.

[16] SANCHEZ-PACHECO,F.J., SOTORRIO-RUIZ,P.J., HEREDIALARRUBIA,J.R., PEREZ-HIDALGO,F., DE CARDONA,M.S.: (2014, Sep.). PLC-based PV plants smart monitoring system: Field measurements and uncertainty estimation, IEEETrans. Instrum. Meas. [Online].63(9), pp. 2215-2222. Available:

http://ieeexplore.ieee.org/document/6775255/ (last accessed: 15th February 2019)

[17] Hengstler (2006, Jan). Hengstler, Your solution for speed and position feedback, for all performance classes and for all climate areas, Hengstler GmbH, Aldingen, Germany. [Online].Available: http://www.hengstler.de/gfx/file/shop/encoder/201201_catalog_ encoder en.pdf

[18] iC-Haus (2002,Nov).BiSS Interface Protocol Description (BiSS C). iC-Haus $\mathrm{GmbH}$, Bodenheim, Germany. [Online].Available: http://www.biss-interface.com/files/BiSS_C_protocol_C6en.pdf(last accessed: 15th February, 2019)

[19] LIBERALI,V., CHERCHI,F., DISINGRINI,L., GOTTARDI,M., GREGORI S., TORELLI,G.: (2003, Feb.). A digital self-calibration circuit for absolute optical rotary encoder microsystems, IEEETrans. Instrum. Meas. [Online].52(1), pp.149-157. Available: http://ieexplore.ieee.org/document/1191423/

[20] ILIĆ,B., MILOSAVLJEVIĆ,M.: Preliminary project of the T-38 wind tunnel control system, Military Tech. Inst., Belgrade, Serbia, Tech. Rep. V3-3091-P-07, Mar. 2011.

[21] ILIĆ,B.: Hibridni system upravljanja strujanjem u aerotunelima velikih brzina, Doktorska disertacija, Mašinski fakultet, Univerzitet u Beogradu, 2017 ("A Hybrid System for Flow Control in High-Speed Wind Tunnels", Ph.D. Dissertation, Faculty of Mechanical Engineering, University of Belgrade, 2017)

[22] National Instruments (2014).NI LabVIEW for CompactRIO Developer's Guide. National Instruments, Austin, TX. [Online]. Available: https://www.ni.com/compactriodevguide/(last accessed: 15th February, 2019)

[23] STEINLE,F., STANEWSKY,E.: Wind tunnel flow quality and data accuracy requirements, NATO AGARD, Paris, France, Adv. Rep. No. 184, Nov. 1982

[24] CLARK,E.: (1994, Jun.). Error propagation equations for estimating the uncertainty in high-speed wind tunnel test results, Presented at $25^{\text {th }}$ Plasmadynamics and Lasers Conference.[Online]. Available: http://arc.aiaa.org/doi/abs/10.2514/6.1994-2588

[25] Mensor (2016, Jun). Calibration technology: Precision pressure sensor, Models CPT6100, CPT6180. WIKA Alexander Wiegand SE \& Co. KG, Klingenberg, Germany. [Online].Available: http://www.wika.rs/upload/DS_CT2510_en_co_34182.pdf (last accessed: 15th February, 2019) 


\title{
FPGA sistem za pozicioniranje aerotunelskog mlaznika promenljive geometrije
}

\begin{abstract}
Zahtevi za tačnošću aerotunelskih ispitivanja su postajali sve strožiji tokom prethodnih nekoliko decenija, usled težnji vazduhoplovne industrije da postigne najbolje performanse svojih proizvoda. Investicije u napredne mogućnosti su neophodne kako bi se tačniji rezultati ispitivanja postizali efikasnije, čime bi se obezbedilo da aerotuneli ostanu produktivni ji u budućnosti. Kao odgovor na ove izazove, u aerotunelu VTI T-38 je primenjen hijerarhijski pristup u projektovanju distribuiranog upravljačkog sistema sa više nivoa. Deo tog sistema je sistem za pozicioniranje mlaznika promenljive geometrije, koji je predstavljen u ovom radu. On prati hijerarhiju kompletnog upravljačkog sistema aerotunela, sa kritičnim upravljačkim petljama smeštenim na FPGA nivou, dok je korisnički interfejs sa mogućnošću obavljanja analiza u realnom vremenu implementiran na centralnom upravljačkom računaru. Pored tačnijeg pozicioniranja, upravljački sistem baziran na FPGA je značajno poboljšao efikasnost, brzinu i pouzdanost rada aerotunela. Kako geometrija mlaznika jednoznačno određuje supersonični Mahov broj u radnom delu aerotunela, poboljšana tačnost pozicioniranja je verifikovana u aerotunelskim ispitivanjima.
\end{abstract}

Ključnereči: mlaznik, aerotunel, FPGA, upravljanje pozicijom, sistem za rad u realnom vremenu, aktuatori, senzori. 